\title{
Human infection caused by Streptococcus suis serotype 2 in China: report of two cases and epidemic distribution based on sequence type
}

Fei Jiang ${ }^{1}$, Jingjing Guo ${ }^{2}$, Chen Cheng $^{3}$ and Bing Gu ${ }^{1,3^{*}}$

\begin{abstract}
Background: Streptococcus suis is a zoonotic pathogen that causes serious systemic infections in pigs and occupation-related infections in humans who contact with pigs or pork products. In China, it has caused two outbreaks of human infection and surveillance for S.suis has been ongoing since last time.

Case presentation: Two cases of meningitis and sepsis caused by S. suis were reported in this study. Both patients work in relation to the pork trade, a risk factor for S. suis infection. The outcome was favorable after a prolonged ceftriaxone therapy but one patient was left with mild hearing loss. Two isolates were identified as sequencing type (ST) 7, S. suis serotype 2 (SS2), which is one the most prevalent and cause two outbreaks in China. Whole-genome sequencing (WGS) revealed that a high degree identity was noted in the genome organizations and sequences between two sporadic ST7 SS2 isolates in this study and representative epidemic virulent isolates. Major differences among them are two sporadic ST7 SS2 isolates lacked a virulence factor called agglutinin receptor and an $89 \mathrm{~K}$ pathogenicity island (PAI), which plays important role in the pathogenesis of streptococcal toxic shock syndrome (STSS). A summary about STs of human infection with S. suis in China was completed. The result showed ST1 and ST7 were still the major STs and several novel STs were successfully discovered in different provinces.

Conclusions: Our results enhanced the understanding of the ability to cause life-threatening infections in humans and the distribution and evolution of the S. suis in China.
\end{abstract}

Keywords: Streptococcus suis, Serotype 2, ST7, Whole-genome sequencing, Case report

\section{Background}

Streptococcus suis is a zoonotic pathogen that causes serious systemic infections in pigs and occupation-related infections in humans who contact with pigs or pork products. The most common clinical manifestations are

\footnotetext{
*Correspondence: gb20031129@163.com

1 Department of Laboratory Medicine, the Affiliated Hospital of Xuzhou Medical University, No.99 West Huaihai Road, Xuzhou 221002, Jiangsu Province, China

${ }^{3}$ Medical Technology School of Xuzhou Medical University, No.209 Tongshan Road, Xuzhou 221004, Jiangsu Province, China

Full list of author information is available at the end of the article
}

meningitis and sepsis. Globally, serotype 2, ST1 isolates have been described as mostly responsible for S. suis human infection, particularly in South America, Europe, Japan, Southeast Asia and China [1]. Serotype 2, ST7 isolates were another predominant sequence type and responsible for the 1998 and 2005 Chinese epidemics, which caused a total of 240 human infections, 52 of whom dead [2]. Surveillance for S.suis has been ongoing since last outbreak in our country [3-5]. Here we report two cases of successfully cured human infection with ST7 SS2. Genomic characteristics were investigated by

(C) The Author(s). 2020 Open Access This article is licensed under a Creative Commons Attribution 4.0 International License, which permits use, sharing, adaptation, distribution and reproduction in any medium or format, as long as you give appropriate credit to the original author(s) and the source, provide a link to the Creative Commons licence, and indicate if changes were made. The images or other third party material in this article are included in the article's Creative Commons licence, unless indicated otherwise in a credit line to the material. If material is not included in the article's Creative Commons licence and your intended use is not permitted by statutory regulation or exceeds the permitted use, you will need to obtain permission directly from the copyright holder. To view a copy of this licence, visit http://creativecommons.org/licenses/by/4.0/. The Creative Commons Public Domain Dedication waiver (http://creativecommons.org/publicdomain/zero/1.0/) applies to the data made available in this article, unless otherwise stated in a credit line to the data. 
WGS and the epidemic distribution of Streptococcus suis isolated from human was summarized based on sequence type in China to better monitoring of this pathogen.

\section{Cases presentation}

In September 2016, a 67-year-old man with an 8-year history of emphysema (case 1) was admitted to the Affiliated Hospital of Xuzhou Medical University because of 2-day history of headache with nausea and fever and 1-day consciousness disturbance. Physical examination revealed neck stiffness and inability to speak, a temperature of $38.7^{\circ} \mathrm{C}$, pulse rate of 110 beats $/ \mathrm{min}$, respiratory rate of 20 breaths/min, and blood pressure of $133 / 80 \mathrm{mmHg}$. A cerebral computed tomography (CT) scan showed no obvious abnormality. Laboratory result for leucocyte cell count was $12.23 \times 10^{9} / \mathrm{L}$ ( $86.4 \%$ neutrophils). Lumbar puncture showed turbid cerebrospinal fluid (CSF) with increased white cell numbers $\left(1807 \times 10^{6} / \mathrm{L}, 82.9 \%\right.$ neutrophils), high protein levels $(2.8 \mathrm{~g} / \mathrm{L})$ and low glucose levels $(1.77 \mathrm{mmol} / \mathrm{L})$. Blood and CSF were collected for culture before empirical meropenem ( $2 \mathrm{~g}$ IV q8h) were prescribed. After 2 days, blood and CSF cultures showed $\alpha$-hemolytic streptococci which was identified as $S$. suis by MALDITOF MS (Bruker Daltonik GmbH, Germany) with a log score 2.369 (above 2.0 is considered reliable for species identification). The patient was diagnosed with purulent meningitis and sepsis. This isolate was susceptible to ampicillin (MIC $\leq 0.25 \mu \mathrm{g} / \mathrm{mL}$ ), penicillin (MIC $\leq 0.06 \mu \mathrm{g} /$ $\mathrm{mL})$, ceftriaxone $(\mathrm{MIC} \leq 0.5 \mu \mathrm{g} / \mathrm{mL})$, vancomycin $(\mathrm{MIC} \leq 1$ $\mu \mathrm{g} / \mathrm{mL}$ ), levofloxacin $(\mathrm{MIC}=2 \mu \mathrm{g} / \mathrm{mL})$, linezolid $(\mathrm{MIC} \leq 2$ $\mu \mathrm{g} / \mathrm{mL}$ ) and meropenem (MIC $\leq 0.25 \mu \mathrm{g} / \mathrm{mL})$, but resistant to erythrocin ( $\mathrm{MIC} \geq 16 \mu \mathrm{g} / \mathrm{mL}$ ), clindamycin (MIC $\geq 8 \mu \mathrm{g} /$ $\mathrm{mL})$, tetracycline $(\mathrm{MIC}=32 \mu \mathrm{g} / \mathrm{mL})$. The patient further reported working as a pork seller. It is a pity that further information regarding whether there was any open wound was not be provided. The antibiotic treatment was replaced by ceftriaxone $2 \mathrm{~g}$ IV $\mathrm{q} 12 \mathrm{~h}$. The patient was successfully treated with no particular adverse events after 24 days.

A previously healthy 48-year-old man (case 2) with a 1-day history of fever and obnubilation was hospitalized to Xuzhou Central Hospital in July 2017. At admission, physical examination showed impaired consciousness, nuchal rigidity and temperature was $38.4{ }^{\circ} \mathrm{C}$, blood pressure 159/98 $\mathrm{mmHg}$, heart rate 105 beats/min, and respiratory rate 46 breaths $/ \mathrm{min}$. CT scan showed bilateral cerebral hemispheres with superficial sulci and cerebral swelling was considered. His leucocyte cell count, procalcitonin and C-reactive protein were $14.89 \times 10^{9} / \mathrm{L}$ (90.5\% neutrophils), $36.42 \mathrm{ng} / \mathrm{mL}$ and $199 \mathrm{mg} / \mathrm{L}$ respectively. CSF had a leukocyte count of $80 \times 10^{6} / \mathrm{L}$, a protein level of $1.3 \mathrm{~g} / \mathrm{L}$ and a glucose level of $2.16 \mathrm{mmol} / \mathrm{L}$. Blood and CSF culture were performed before empirical application of ceftriaxone ( $\mathrm{g}$ IV q12h). After 3 days, blood and CSF cultures showed $\alpha$-hemolytic grampositive streptococci. The isolate was identified as S.suis by MALDI-TOF MS with a log score 2.230 and showed susceptibility to ampicillin (MIC $\leq 0.25 \mu \mathrm{g} / \mathrm{mL}$ ), penicillin (MIC $\leq 0.06 \mu \mathrm{g} / \mathrm{mL}$ ), ceftriaxone (MIC $\leq 0.5 \mu \mathrm{g} / \mathrm{mL}$ ), vancomycin $(\mathrm{MIC} \leq 1 \mu \mathrm{g} / \mathrm{mL})$, levofloxacin $(\mathrm{MIC}=2 \mu \mathrm{g} / \mathrm{mL})$, linezolid (MIC $\leq 2 \mu \mathrm{g} / \mathrm{mL}$ ), meropenem (MIC $\leq 0.25 \mu \mathrm{g} / \mathrm{mL}$ ), erythrocin (MIC $\leq 0.25 \mu \mathrm{g} / \mathrm{mL}$ ), clindamycin $\quad(\mathrm{MIC} \leq 0.25$ $\mu \mathrm{g} / \mathrm{mL}$ ) and only resistance to tetracycline (MIC $=32 \mu \mathrm{g} /$ $\mathrm{mL}$ ). After $S$. suis was identified, the patients reported engaging in the cooked food selling as a profession. And before he became ill, he contacted a sick dead pig with a wound on his hand. This patient was diagnosed with purulent meningitis and sepsis and he improved on administration with ceftriaxone $2 \mathrm{~g}$ IV q12h for 15 days and methylprednisolone $80 \mathrm{mg}$ IV qd for 4 days, followed by $40 \mathrm{mg}$ IV qd for 7 days and $20 \mathrm{mg}$ IV qd for 4 days. However, pure tone audiology evaluation showed mild bilateral hearing loss $(-40 \mathrm{~dB})$. The patient's hearing ability was not normalized in 2 months of follow-up after discharge.

Further analysis was performed to investigate their characteristics of these two isolates. Multilocus sequence typing (MLST) determined that two isolates assigned to ST7, which was the most predominant sequence type in China [1]. On eBURST v.3.0 analysis (Fig. 1), ST7 belongs to the clone complex 7 (CC7) and is a single-locus variant (SLV) of ST1. Two isolates were serotyped by multiplex PCR (a technique that cannot differentiate serotype 2 from $1 / 2$ and serotypes 1 and 14) and confirmed as serotype 2 by WGS data (Fig. 2a, b) and the $S$. suis serotyping pipeline (https://github.com/streplab/ SsuisSerotyping_pipeline). The pipeline uses the cpsK gene (Streptococcus suis NSUI002, GenBank accession number CP011419) missense mutation at position 161 to differentiate serotypes 2 and $1 / 2$.

Comparing to genome of representative epidemic isolates (05ZYH33 and 98HAH33) [3], a high degree identity was noted in the genome organizations and sequences. Two sporadic ST7 isolates carried all virulence factors except agglutinin receptor. In addition, the major difference in genome of two sporadic ST7 isolates in this study was the absence of $89 \mathrm{~K}$ PAI specific to epidemic isolates, which play an important role in the pathogenesis of STSS.

According to the MLST database (https://pubmlst.org/ ssuis) and previous geographic reviews [1,3-6], we summarized and mapped the geographic distribution of S.suis causing human infection in China. The collected epidemiological data showed that $S$. suis cases occur mainly in South China. Except for two large outbreaks occurred in 1998 and 2005, other human infection cases were sporadic infections. ST1 and ST7 were still the main sequence types relevant to $S$. suis human infection in China. Meanwhile, several novel sequence types 


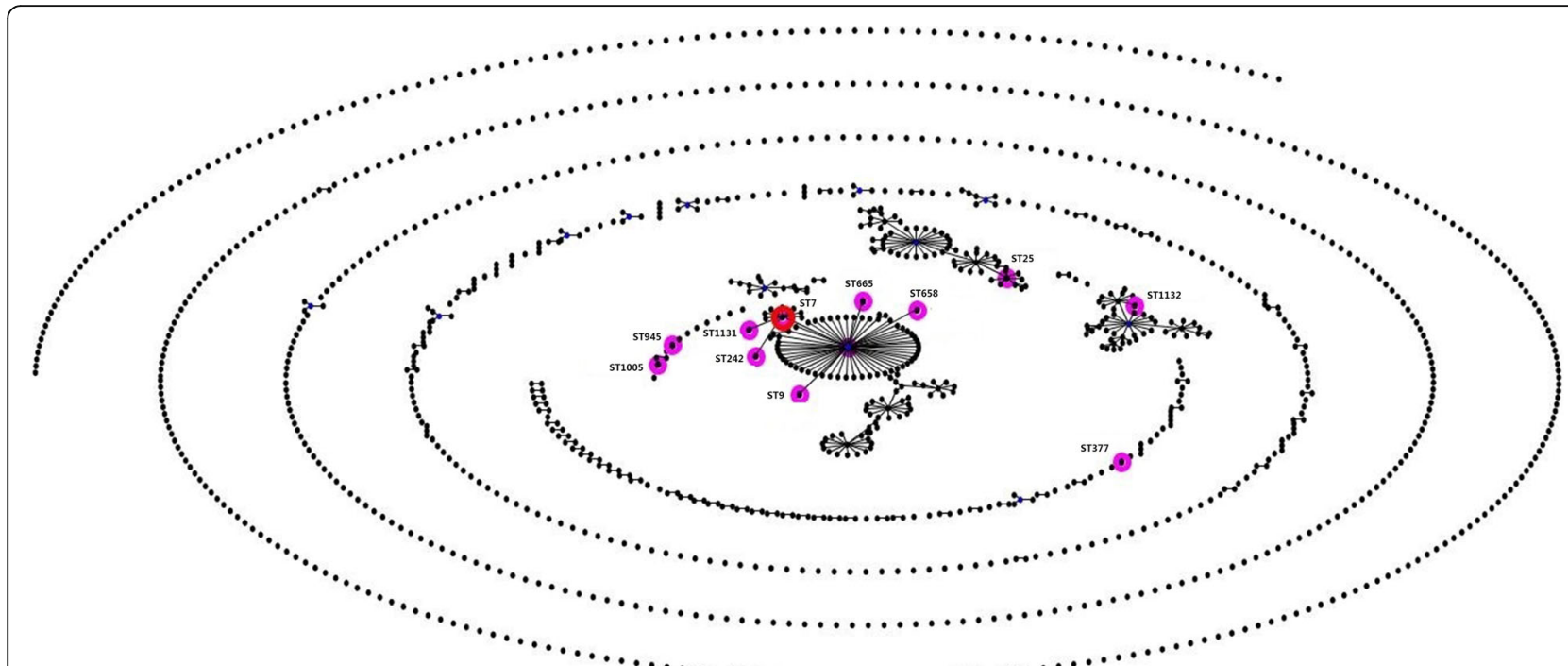

Fig. 1 An eBURST analysis of the S. suis MLST database (accessed on July 18, 2019). The sequence types found in China was marked with pink circles. ST7 S. suis in this study belonged to CC7 (red circle)

(ST242, ST377, ST658, ST665, ST945, ST1005, ST1131 and ST1132) were gradually discovered in different provinces in recent years (Fig. 3). Additional concerns should be raised because of the high pathogenicity of these microbes. It is interesting that these newly discovered STs were found exclusively in humans according to MLST database. As a zoonotic pathogen, S. suis is primarily and usually found in pigs and there is no direct evidence to date showing human-to-human infection [7]. Therefore, future work should focus on a broader sampling from humans and pigs and comparative analyses between them.

\section{Discussion and conclusions}

Human infection caused by $S$. suis is a rare but lifethreatening condition. Epidemic and sporadic human infection cases caused by $S$. suis serotype 1, 2, 4, 5, 9, 14, $16,21,24$ and 31 have also been reported in many countries and $17.8 \%$ of patients dead [1, 8-10].Timely and accurate diagnosis of pathogenic bacteria is the key to cure. Because of the variable of biochemical characteristics, S. suis is often misidentified as other species of Streptococcus genus [7]. MALDI-TOF MS is a rapid and accurate technique used to detect isolates of S.suis. In addition to serum agglutination, specific multiple PCR was developed for serotype analysis, but cannot distinguish serotype 2 from serotype $1 / 2$ [11]. In a recent report, serotype and genotype (multilocus sequence type) of isolates has been demonstrated to serve as predictors of pathotype [12]. Thus, serological evidence or analysis of the cps locus based on WGS and ST were essential to investigate the pathogenic pathotype. STs of SS2 were diverse worldwide, such as ST1 and ST147 in Europe, ST1, ST7, ST25 and ST28 in Asia, ST25 and ST28 in North America and ST1 in South America [1]. Obviously ST1 was the most predominant. However, ST7, to which two isolates in this study belong, has caused the 1998 and 2005 outbreaks of human infection relative to sporadic infections caused by ST1 in China $[8,13]$. At the same time, newly sequence types were gradually discovered in recent years and additional concern should be raised to prevent potential large-scale spread.

As well-recognized to be a highly virulent, epidemic ST7 SS2 isolates carried lots of virulence factors [14]. An $89 \mathrm{~K}$ PAI, correlated with STSS and high pathogenicity to some extent, was confirmed to be prevalent and unique among the extremely virulent SS2 isolates that are responsible for both large scale outbreaks of severe human SS2 infections in China [15]. Through the annotation of virulence factors of pathogenic bacteria, we did not find centralized and continuous virulence genes. At the same time, we compared the assembled results with S. suit-related virulence islands and no virulence island region existed in these two isolates. This explains the absence of STSS in our patients. Whether agglutinin receptor plays an important role in the pathogenicity of $S$. suis will be further investigated.

Wound exposure to pigs and pork is considered to be one of the most important ways to contract S. suis. Human infections duo to consumption of raw pork products suggest that the gastrointestinal tract is also a major route of entry in cases of $S$. suis infections, especially in patients with damage to the intestinal barrier [16]. In our cases, both case-patients were at risk for 

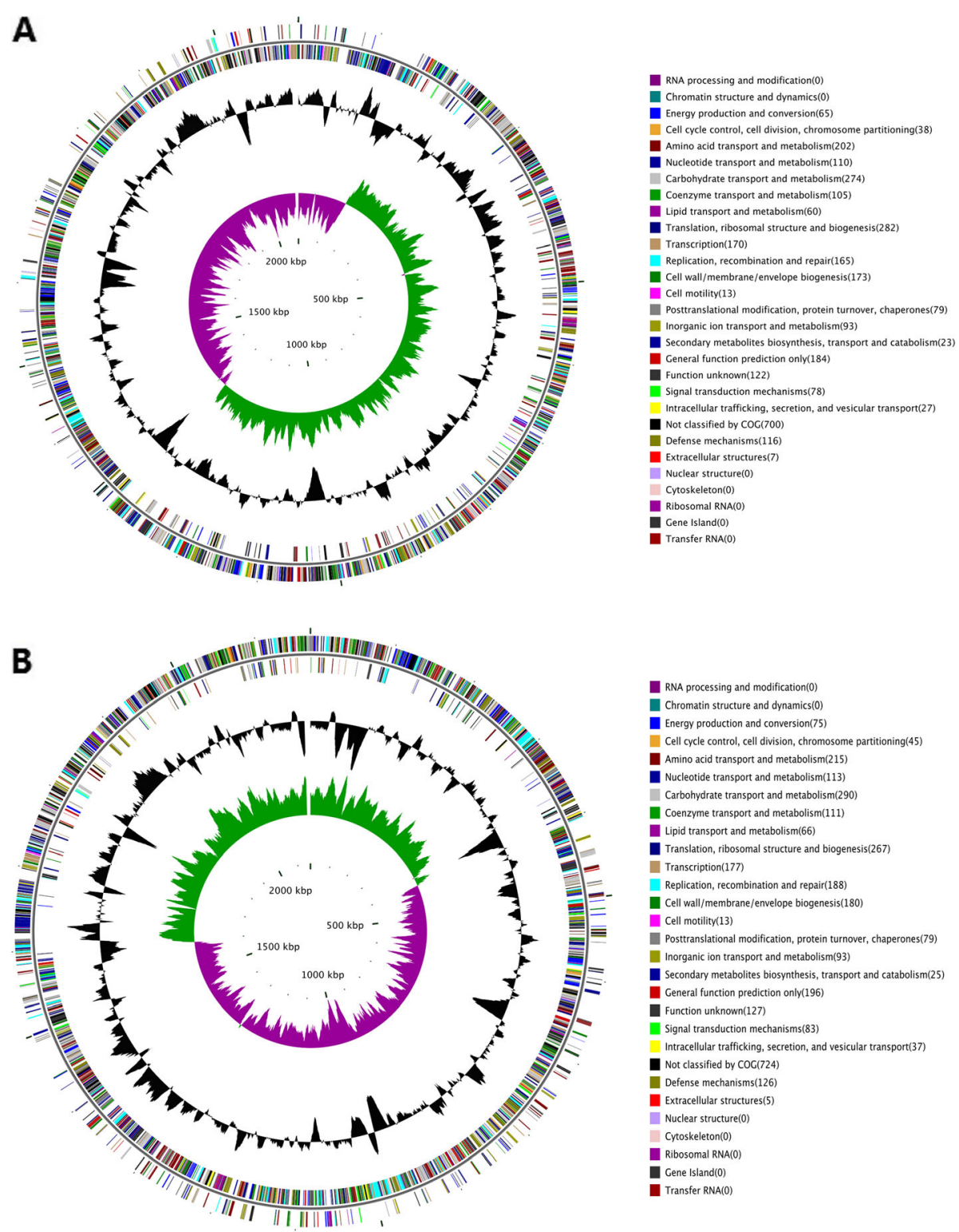

Fig. 2 Circular diagrams and in silico comparison of two S. suis genomes(S.suis1 (a) and S.suis2 (b)) . From outside to inside, in circle 1, the coding genes of COG outside (inside) represent the genes located on the positive (negative) strand, different colors represent different biological functions. In circle 2 (black circle), the GC contents of the genomes were shown. In circle 3, GC skew $[(G-C) /(G+C)]$ is displayed (Green indicates values $>0$, and purple indicates values $<0$ )

infection because their profession was engaged in the pork trafficking, and one patient contacted a sick dead pig with an open wound on his hand, suggesting the source of the infection. Because breakpoints for S. suis are not defined in the Clinical and Laboratory Standards Institute guidelines, breakpoints for Streptococci viridians were used instead in this study [17]. Results of antibiotic sensitivity test showed that two isolates were sensitive to most antibacterial agents. It is reported that $99.1 \%$ S. suis was resistant to tetracycline and $67.9 \%$ to erythromycin and clindamycin because of the present of tet and erm resistance genes [18]. We did not perform the detection because erythromycin and tetracycline was not the preferred drug for treating S.suis infection. According to the previous literature [19], a prolonged treatment course and close monitoring of patients upon completion of therapy for signs and symptoms of recrudescent disease were suggested and if symptoms recur, an additional treatment course based on clinical response will be considered. 


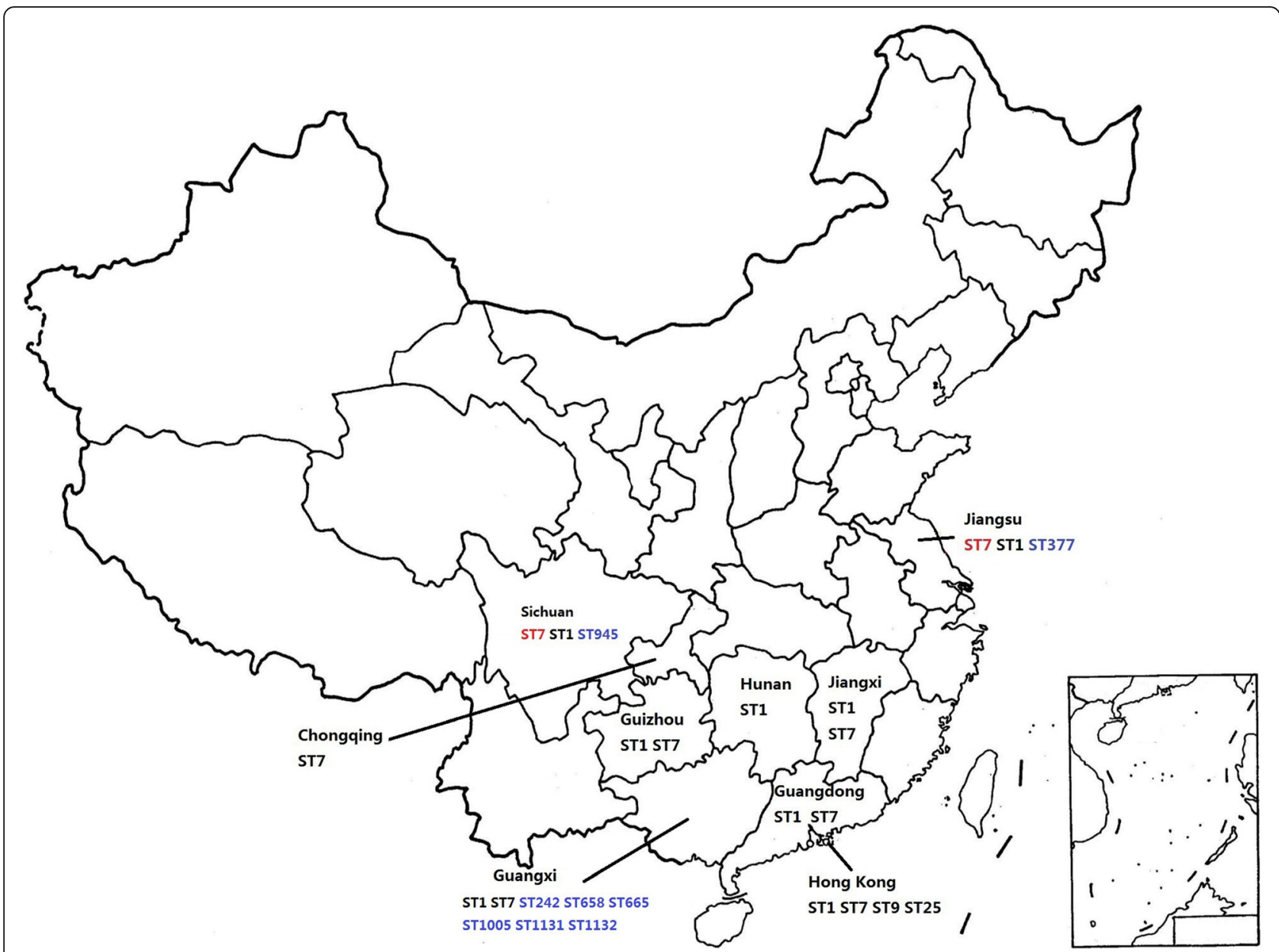

Fig. 3 Geographic distribution of human S. suis infections based on ST in China. Two large-scale outbreaks caused by ST7 are indicated in red and the newly discovered STs are labeled in blue. All other sporadic cases are presented in black

Our results enhanced the understanding of the distribution and evolution of the S. suis and their ability to cause life-threatening infections in humans. ST1 and ST7 are still predominant in China and newly STs should also be strict monitored to prevent potential spread.

\section{Abbreviations}

CSF: Cerebrospinal fluid; CT: Computed tomography; MALDI-TOF MS: Matrixassisted laser desorption ionization-time of flight mass spectrometry; MIC: Minimum inhibitory concentration; PAl: Pathogenicity island; S. suis: Streptococcus suis; ST: Sequence type; WGS: Whole-genome sequencing

\section{Acknowledgements}

We thank Jianwei Chen (BGI-Qingdao) for technical support and bioinformatics knowledge during the sequencing process.

\section{Authors' contributions}

BG participated in manuscript revision. JG provided clinical data. FJ and CC performed the experiments.FJ drafted the manuscript. All authors reviewed and approved the final manuscript.

\section{Funding}

This work was financially supported by the National Natural Science Foundation of China (81471994). The funder (BG) was the corresponding author and participated in manuscript revision.
Availability of data and materials

All original data used and analyzed during the current study are available from the corresponding author on reasonable request. The datasets generated and analyzed during the current study are available in the CNSA repository. (CNSA project ID: CNP0000908. Accession numbers: CNA0007340 and CNA0007341. https://db.cngb.org/cnsa/project/CNP0000908/reviewlink/).

Ethics approval and consent to participate Not applicable.

\section{Consent for publication}

Written consent was obtained from two patients for publication of this report.

\section{Competing interests}

The author(s) declare that they have no competing interests.

\section{Author details}

'Department of Laboratory Medicine, the Affiliated Hospital of Xuzhou Medical University, No.99 West Huaihai Road, Xuzhou 221002, Jiangsu Province, China. ${ }^{2}$ Department of Laboratory Medicine, Xuzhou Central Hospital, No.199 South Jiefang Road, Xuzhou 221009, Jiangsu Province, China. ${ }^{3}$ Medical Technology School of Xuzhou Medical University, No.209

Tongshan Road, Xuzhou 221004, Jiangsu Province, China. 
Received: 24 July 2019 Accepted: 2 March 2020

Published online: 14 March 2020

\section{References}

1. Goyette-Desjardins G, Auger JP, Xu J, Segura M, Gottschalk M. Streptococcus suis, an important pig pathogen and emerging zoonotic agent-an update on the worldwide distribution based on serotyping and sequence typing. Emerg Microbes Infect. 2014;3(6):e45. https://doi.org/10.1038/emi.2014.45.

2. Lun Z, Wang Q, Chen X, Li A, Zhu X. Streptococcus suis: an emerging zoonotic pathogen. Lancet Infect Dis. 2007;7(3):201-9. https://doi.org/10. 1016/S1473-3099(07)70001-4

3. Zhou Y, Dong XX, Li ZW, Zou G, Lin L, Wang XH, et al. Predominance of Streptococcus suis ST1and ST7 in human cases in China, and detection of a novel sequence type, ST658. Virulence. 2017;8(6):1031-5. https://doi.org/10. 1080/21505594.2016.1243193.

4. Huang WH, Wang ML, Hao HJ, Yang RF, Xie JJ, Su JH, et al. Genomic epidemiological investigation of a Streptococcus suis outbreak in Guangxi, China, 2016. Infect Genet Evol. 2019;68:249-52. https://doi.org/10.1016/j. meegid.2018.12.023.

5. Wang ML, Du PC, Wang JP, Lan RT, Huang J, Luo M, et al. Genomic Epidemiology of Streptococcus suis Sequence Type 7 Sporadic infections in the Guangxi Zhuang Autonomous Region of China. Pathogens. 2019;8(4): E187. https://doi.org/10.3390/pathogens8040187.

6. Li W, Ye CY, Jing HQ, Cui ZG, Bai XM, Jin D, et al. Streptococcus suis outbreak investigation using multiple-locus variable tandem repeat number analysis. Microbiol Immunol. 2010;54(7):380-8. https://doi.org/10.1111/j.1348-0421. 2010.00228.x.

7. Gottschalk M, Xu J, Calzas C, Segura M. Streptococcus suis: a new emerging or an old neglected zoonotic pathogen? Future Microbiol. 2010;5(3):371-91. https://doi.org/10.2217/fmb.10.2.

8. Ye CY, Zhu XP, Jing HQ, Du HM, Mariela S, Zheng H, et al. Streptococcus suis sequence type 7 outbreak, Sichuan, China. Emerg Infect Dis. 2006;12(8): 1203-8. https://doi.org/10.3201/eid1208.060232.

9. Hatrongjit R, Kerdsin A, Gottschalk M, Takeuchi D, Hamada S, Oishi K, et al. First human case report of sepsis due to infection with Streptococcus suis serotype 31 in Thailand. BMC Infect Dis. 2015;15(1):392. https://doi.org/10. 1186/s12879-015-1136-0.

10. Kerdsin A, Hatrongjit R, Gottschalk M, Takeuchi D, Hamada S, Akeda Y, et al. Emergence of Streptococcus suis serotype 9 infection in human. J Microbiol Immunol Infect. 2017;50(4):545-6. https://doi.org/10.1016/j.jmii.2015.06.011.

11. Kerdsin A, Akeda Y, Hatrongjit R, Detchawna U, Sekizaki T, Hamada S, et al. Streptococcus suis serotyping by a new multiplex PCR. J Med Microbiol. 2014;63(Pt 6):824-30. https://doi.org/10.1099/jmm.0.069757-0.

12. Estrada AA, Gottschalk M, Rossow S, Rendahl A, Gebhart C, Marthaler DG. Serotype and genotype (multilocus sequence type) of Streptococcus suis isolates from the United States serve as predictors of Pathotype. J Clin Microbiol. 2019;57(9):e00377-19. https://doi.org/10.1128/JCM.00377-19.

13. He JH, Wang JC, Lin JH. Advances in Streptococcus suis type 2-a new zoonosis pathogen. AnimHusb Vet Med. 2001;33:38-40 (in Chinese).

14. Feng YJ, Zhang HM, Ma Y, Gao GF. Uncovering newly emerging variants of Streptococcus suis, an important zoonotic agent. Trends Microbiol. 2010; 18(3):124-31. https://doi.org/10.1016/j.tim.2009.12.003.

15. Chen C, Tang JQ, Dong W, Wang CJ, Feng YJ, Wang J, et al. A glimpse of streptococcal toxic shock syndrome from comparative genomics of S. suis 2 Chinese isolates. PLoS One. 2007;2(3):e315. https://doi.org/10.1371/journal. pone.0000315

16. Kerdsin A, Dejsirilert S, Sawanpanyalert P, Boonnark A, Noithachang W, Sriyakum D, et al. Sepsis and spontaneous bacterial peritonitis in Thailand. Lancet. 2011;378(9794):960. https://doi.org/10.1016/S0140-6736(11)60923-9.

17. CLSI. Methods for dilution antimicrobial susceptibility tests for bacteria that grow aerobically. 11th ed. CLSI standard M07. Wayne: Clinicaland Laboratory Standards Institute; 2018. Available from: http://clsi2018m0711th.pdf. Accessed Jan 2018.

18. Chen L, Song YJ, Wei ZG, He HK, Zhang AD, Jin ML. Antimicrobial susceptibility, tetracycline and erythromycin resistance genes, and multilocus sequence typing of Streptococcus suis isolates from diseased pigs in China. J Vet Med Sci. 2013;75(5):583-7. https://doi.org/10.1292/jvms.12-0279.

19. Dejace J, Bagley P, Wood E. Streptococcus suis meningitis can require a prolonged treatment course. Int J Infect Dis. 2017;65:34-6. https://doi.org/ 10.1016/j.jijid.2017.09.011.

\section{Publisher's Note}

Springer Nature remains neutral with regard to jurisdictional claims in published maps and institutional affiliations.

\section{Ready to submit your research? Choose BMC and benefit from:}

- fast, convenient online submission

- thorough peer review by experienced researchers in your field

- rapid publication on acceptance

- support for research data, including large and complex data types

- gold Open Access which fosters wider collaboration and increased citations

- maximum visibility for your research: over $100 \mathrm{M}$ website views per year

At BMC, research is always in progress.

Learn more biomedcentral.com/submissions 